\title{
The Challenge of Feedback Personalization to Learning Styles in a Web- Based Learning System
}

\author{
Ekaterina Vasilyeva \\ Dept. of CS and ISs \\ University of Jyväskylä \\ ekvasily@cc.jyu.fi
}

\author{
Mykola Pechenizkiy \\ Dept. of Math. Inf. Tech. \\ University of Jyväskylä \\ mpechen@cs.jyu.fi
}

\author{
Seppo Puuronen \\ Dept. of CS and ISs \\ University of Jyväskylä \\ sepi@cs.jyu.fi
}

\begin{abstract}
Feedback is information that is provided to a user to inform him/her about the result of his/her action and to motivate him/her to further interact with the system. In web-based learning systems (WBLS), feedback is particularly important in test and evaluation tasks. The main objective of the paper is twofold: (1) to encourage WBLS designers and specialists to pay more attention to the problem of feedback adaptation, and (2) to analyze suggestions for feedback personalization to learning styles in a WBLS.
\end{abstract}

\section{Introduction}

Feedback is a response to (a) user's action(s) and it is provided to a user to compare his/her performance with the expected one [5]. The main role of feedback in a Web-Based Learning System (WBLS) is to inform and motivate a user to increase his/her effort and attention. Feedback can differ in the content, time, and manner of presentation. Personalization of feedback offers possibilities to adapt it to be the most appropriate for the user's expertise and cognitive abilities in general and, in particular, to his/her current mood and attentiveness.

The goal of this paper is to analyze the challenges of feedback personalization to the learning styles (LSs) of users and to consider recommendations for feedback design and adaptation in a WBLS. We analyse recently published results of adaptation research concerning LS based personalization in the WBLS context and dissect them against our taxonomy of feedback adaptation [5].

\subsection{Feedback in a WBLS}

In a WBLS, feedback plays a crucial role in interaction. The feedback is especially important in test and assessment tasks incorporated into the learning process implemented within a WBLS.
In a WBLS, feedback can differ in its function (confirming, informing, correcting, explaining, motivating, rewarding, or evaluating), complexity (nofeedback, knowledge-of-response, knowledge-ofcorrect-response, answer until correct, or elaborated), time of occurrence (immediate or delayed feedback), user's progress within a task (immediate, continuous, or summative), and way of presentation (textual, visual, audio, or video) [5]. Thus feedback adaptation offers a wide range of possibilities to provide a user with appropriate feedback in the WBLS context [5].

\subsection{Adaptation and Learning Styles}

According to Stash and De Bra [4], there is no consensus whether it is reasonable or not to apply LS in an adaptive hypermedia learning systems design. Nevertheless, a number of researches on the adaptation of WBLSs to individual LSs have recently demonstrated that users from different groups of LSs showed distinct reactions to the interaction with hypermedia learning environments.

Different systems provide adaptation according LSs in terms of content adaptation, navigation paths, or usage of multiple navigational tools. Most of the adaptive WBLSs, which incorporate learning styles, are based on the notion that matching learner's learning strategy with the LS improves his/her performance [3]. According to our knowledge, there is no reported research concentrated on the feedback adaptation based on LS in the WBLS context.

\section{Feedback Personalization to LSs in a WBLS}

In this section we summarize feedback personalization recommendations based on individual LS using two classifications (Table 1) based on two models: 1) Field dependence/Field independence model of Witkin et al. (FD/FI -model) [6] and 2) four- 
dimensional LS model of Felder and Silverman (F-S model) [2]. We emphasize two main aspects of feedback: 1) the informational aspect (what is presented in the feedback) and the motivational one (when and how feedback is presented).

\subsection{The FD/FI -model}

$\mathrm{FD} / \mathrm{FI}$ dimension is particularly important for a WBLS, as it characterizes the degree to which a learner's perception or comprehension of information is affected by the surrounding perceptual or contextual field. $F D$-oriented users require additional reinforcements and navigational support, while $F I$ oriented users require minimal guidance and direction $[4,6]$.

\subsection{The F-S -model}

Felder-Silverman's four-dimensional (activereflective, sensing-intuitive, visual-verbal, and sequential-global) model [2] is considered as the best suited and feasible LS theory with respect to WBLS design and development [1].

Table 1. Feedback Adaptation Recommendations Grouped According to FD/FI and F-S -models

\begin{tabular}{|c|c|}
\hline \multicolumn{2}{|c|}{ Feedback Adaptation to Learning Styles } \\
\hline Field Dependent (FD, Sequential) & Field Independent (FI, Global) \\
\hline $\begin{array}{l}\text { - Provide always immediate feedback; } \\
\text { - Present feedback in the main window (not in a new or pop-up } \\
\text { window); } \\
\text { - Do not use hyperlinks in the feedback text; } \\
\text { - Present the correct answer and short explanations; } \\
\text { - Praise always the correct answers; } \\
\text { - Use media effects (sounds, animation) to motivate the user. }\end{array}$ & $\begin{array}{l}\text { - Present continuous feedback that demonstrates user's } \\
\text { progress within the task; } \\
\text { - Use grades to motivate; } \\
\text { - Do not use many uninformative media effects (audio effects, } \\
\text { animation, etc.); } \\
\text { - Present elaborated feedback that includes hyperlinks to the } \\
\text { learning materials corresponding to the question. }\end{array}$ \\
\hline Active & $\begin{array}{l}\text { Reflective } \\
\end{array}$ \\
\hline $\begin{array}{l}\text { - Present answer until correct feedback; } \\
\text { - Use external rewards collected within the test to motivate } \\
\text { - Present animation elements in feedback. }\end{array}$ & $\begin{array}{l}\text { - Present feedback in a new window and time to process it; } \\
\text { - Provide elaborated feedback; } \\
\text { - Do not use audio as a main source of feedback. }\end{array}$ \\
\hline Sensing & Intuitive \\
\hline $\begin{array}{l}\text { - Present immediate feedback; } \\
\text { - Do not provide continuous feedback; } \\
\text { - Use different types of media for feedback (verbal, visual, } \\
\text { audio, tactile); } \\
\text { - Present corrective feedback or elaborated feedback with brief } \\
\text { theoretical summary or practical explanations. }\end{array}$ & $\begin{array}{l}\text { - Provide immediate corrective or elaborated feedback with } \\
\text { brief theoretical explanation only in the case of an incorrect } \\
\text { answer; } \\
\text { - Present continuous feedback; } \\
\text { - Do not use many multimedia effects (audio, animation or } \\
\text { video) in feedback presentation. }\end{array}$ \\
\hline Verbaliser & Visualiser (Imager) \\
\hline $\begin{array}{l}\text { - Present feedback as a text or in figures; } \\
\text { - Use feedback in audio form (verbal praising, etc). }\end{array}$ & $\begin{array}{l}\text { - Use more graphic information in feedback presentation } \\
\text { (pictures, diagrams, charts, animation and short movies). }\end{array}$ \\
\hline
\end{tabular}

\section{Conclusions}

Feedback adaptation in the WBLS context has been studied very selectively in the e-Learning research communities. Therefore, the results of our summarizing analysis of recommendations are highly speculative and await further validation in extensive experimental studies. These experimental studies are necessary to discover the positive patterns of relations between individual LSs and the adaptable feedback parameters increasing the efficiency of interaction and learning processes. The results of experiments should obtain useful and actionable knowledge that could be used by an adaptation engine of a WBLS.

Acknowledgements. This research is partly supported by the Nokia Foundation and COMAS Graduate School of the University of Jyväskylä, Finland.

\section{References}

[1] C.A. Carver, R.A. Howard, and W.D. Lane, "Addressing different learning styles through course hypermedia", IEEE Transactions on Education, 42 (1), 1999, pp. 33-38.

[2] R.M. Felder, and L.K. Silverman, "Learning and teaching styles in engineering education", $J$. of Engineering Education, 78(7), 1988, pp. 674-681.

[3] N. Stash, A. Cristea, and P. De Bra, "Authoring of Learning Styles in Adaptive Hypermedia: Problems and Solutions", Proc. WWW Conference, 2004, New York, USA. [4] N. Stash, and P. De Bra, "Incorporating cognitive styles in AHA!", Proc. of the IASTED International Conference Web-Based Education, 2004, pp. 378-383.

[5] E. Vasilyeva, S. Puuronen, M. Pechenizkiy, and P. Räsänen, "Feedback adaptation in web-based learning systems", (under review) Special Issue of IJCEELL, 2006.

[6] H.A Witkin, C.A. Moore, D.R. Goodenough, and P. W. Cox, "Field-dependent and field-independent cognitive styles and their educational implications", Review of Educational Research, 47(1), 1977, pp. 1-64. 